\title{
DNA extract characterization process for microbial detection methods development and validation
}

\author{
Nathan D Olson and Jayne B Morrow*
}

\begin{abstract}
Background: Quantitative polymerase chain reaction ( $\mathrm{PPCR}$ ) assays used in pathogen detection require rigorous methods development including characterizing DNA extraction products. A DNA extract characterization process is demonstrated using DNA extracted from five different cells types (two Gram-negatives: Escherichia coli, and Burkholderia thailandensis, spores and vegetative cells from the Gram-positive Bacillus cereus, and yeast Saccharomyces cerevisiae) with six different methods.

Results: DNA extract quantity (concentration and extraction efficiency) and quality (purity and intactness) varied by cell type and extraction method enabling the demonstration of different DNA characterization methods. DNA purity was measured using UV spectroscopy, where the $A_{260} / A_{280}$ and $A_{260} / A_{230}$ ratios are indicators of different contaminants. Reproducibility of UV spectroscopy measurements decreased for DNA concentrations less than $17.5 \mathrm{ng} / \mu \mathrm{L}$. Forty-seven extracts had concentrations greater than $17.5 \mathrm{ng} / \mu \mathrm{L}, 25$ had $\mathrm{A}_{260} / \mathrm{A}_{280}$ above 2.0 , and 28 had $A_{260} / A_{230}$ ratios below 1.8 indicating RNA and polysaccharide contamination respectively. Based on a qPCR inhibition assay the contaminants did not inhibit PCR. Extract intactness was evaluated using microfluidic gel electrophoresis. Thirty-five samples had concentrations above the limit of quantification (LOQ, roughly $11 \mathrm{ng} / \mu \mathrm{L})$, 93.5\% of the DNA was larger than $1 \mathrm{~kb}$ and $1 \%$ was smaller than $300 \mathrm{bp}$. Extract concentrations ranged from $1502.2 \mathrm{ng} / \mu \mathrm{L}$ to below the LOQ when UV spectroscopy, fluorometry, and GPCR were used. LOQ for UV spectroscopic and fluorometric measurements were $3.5 \mathrm{ng} / \mu \mathrm{L}$ and $0.25 \mathrm{ng} / \mu \mathrm{L}$ respectively. The $\mathrm{qPCR} L O Q$ varied by cell type $\left(5.72 \times 10^{-3} \mathrm{ng} / \mu \mathrm{L}\right.$ for E. coli, $2.66 \times 10^{-3} \mathrm{ng} / \mu \mathrm{L}$, for $B$. cereus, $3.78 \times 10^{-3} \mathrm{ng} / \mu \mathrm{L}$ for $B$. thailandensis, and $7.67 \times 10^{-4} \mathrm{ng} / \mu \mathrm{L}$ for S. cerevisiae). A number of samples were below the UV spectroscopy ( $\left.n=27\right)$, flurometry $(n=15)$, and $q P C R(n=3) L O Q$.

Conclusion: The presented DNA extract characterization process provides measures of DNA quantity and quality applicable to microbial detection methods development and validation studies. Evaluating DNA quality and quantity results in a better understanding of process LOD and contributing factors to suboptimal assay performance. The samples used demonstrated the use of different DNA characterization methods presented but did not encompass the full range of DNA extract characteristics.
\end{abstract}

Keywords: DNA extraction, DNA characterization, DNA concentration, DNA purity, Shearing, PCR inhibition, qPCR, Biodetection

\footnotetext{
* Correspondence: jayne.morrow@nist.gov

Biosystems and Biomaterials Division, Material Measurements Laboratory,

National Institute of Standard and Technology, 100 Bureau Dr, Gaithersburg

20899-8312, Maryland
}

\section{Biomed Central}

C 2012 Olson and Morrow; licensee BioMed Central Ltd. This is an Open Access article distributed under the terms of the Creative Commons Attribution License (http://creativecommons.org/licenses/by/2.0), which permits unrestricted use, distribution, and reproduction in any medium, provided the original work is properly cited. 


\section{Background}

Developments in molecular based microbial detection methods, such as quantitative polymerase chain reaction (qPCR) [1], have significantly contributed to rapid identification and quantification of unknown biological agents [2]. Public health, and clinical laboratories are often tasked with developing qPCR-based assays for detecting unknown pathogens in complex matrices [3,4]. Microbial detection assay development requires optimizing deoxyribonucleic acid (DNA) extraction and qPCR detection assays. DNA extraction is a multi-step process including; lysing the cell wall, isolating the DNA from other cellular materials, and eluting the DNA in a buffer suitable for downstream applications [5]. High sensitivity detection assays require DNA extraction methods with high efficiency, removal of PCR inhibitors, and DNA larger than PCR assay targets [1]. DNA extracts must meet application requirements or assays may result in false negatives with serious consequences [6]. DNA extraction method suitability is determined by characterizing the extracted DNA's quantity and quality. DNA quantity is an indicator of extraction efficiency and quality parameters (purity and intactness) indicate DNA is free of PCR inhibitors and appropriately sized. DNA quality (purity and intactness) and quantity are evaluated with a number of different techniques.

DNA quality is characterized in terms of purity using UV spectroscopy, presence of inhibitors using a PCR inhibition assay, and intactness using gel electrophoresis. UV spectroscopy is used to evaluate DNA purity by measuring a sample's absorbance spectrum between 200 and $320 \mathrm{~nm}$, and calculating the $\mathrm{A}_{260} / \mathrm{A}_{280}$ and $\mathrm{A}_{260} / \mathrm{A}_{230}$ ratios [7]. The two-absorbance ratios indicate different contaminants and extract suitability for different applications. For example the $A_{260} / A_{230}$ absorbance ratio is a better indicator of suitability for microarrays whereas the $A_{260} / A_{280}$ ratio is a better indicator for PCR [8]. Ratios between 1.8 and 2.0 for $\mathrm{A}_{260} / \mathrm{A}_{280}$ are accepted as indicating pure DNA [9]. RNA and protein contamination are indicated by $\mathrm{A}_{260} / \mathrm{A}_{280}$ ratios above and below 1.8 and $2.0[7,10]$. For the $A_{260} / A_{230}$ ratio the community accepted range is 1.8 to 2.2 [9], values below this range can indicate phenol, salt, protein or polysaccharide contamination $[7,9]$. PCR inhibitors, or impurities that interfere with DNA polymerase, lowering PCR efficiency, are assayed for using an inhibition control assay where a known number of exogenous DNA plasmids are added to the extracted DNA and evaluated using $\mathrm{qPCR}$. The presence of PCR inhibitors is identified by an increase in the threshold cycle $\left(C_{t}\right)$ value for inhibition reactions compared to control reactions. Similarly, DNA fragment size influences detection assay efficiency [11], as efficiency decreases when the qPCR target is fragmented, preventing amplification. Gel electrophoresis is used to evaluate the size distribution of the extracted DNA fragments.

Additional measurement methods are used to evaluate DNA extracts for concentration, and extraction efficiency. DNA quantity is normally measured using three methods: UV spectroscopy, fluorometry, and qPCR. Other methods such as digital PCR and phosphorus elemental analysis are available but not commonly used in diagnostic labs due to specialized equipment requirements, or the amount of DNA required (500 $\mu \mathrm{g}$ for elemental analysis) [12-14]. Two important parameters used to describe quantitative measurement method performance are the limit of detection (LOD, the smallest confidently detected measureable quantity) and the limit of quantitation (LOQ, is the smallest quantity with acceptable repeatability and trueness measurements) [15]. The LOD and LOQ and upper limit of detection vary for UV spectroscopy, flourometry and qPCR. The upper measurement limit is less of a concern compared to the lower limits as the extracts can be diluted to within the measurements working range.

Nucleic acids strongly absorb UV light with wavelengths of $260 \mathrm{~nm}$ due to the resonance structure of the purine and pyrimidine bases [7]. The absorbance is converted into $\mathrm{ng} / \mu \mathrm{L}$ of double stranded DNA (dsDNA) using the established conversion factor of $50 \mathrm{ng} / \mu \mathrm{L}$ for 1 optical density unit at $260 \mathrm{~nm}$ [9]. Other common impurities (including RNA and protein) also absorb at $260 \mathrm{~nm}$, causing the DNA concentration to be overestimated, but do not affect the detection process LOD unless they inhibit the qPCR detection assay. UV absorbance linear range includes absorbance values $\left(\mathrm{A}_{260 \mathrm{~nm}}\right)$ ranging from 0.1 to 1.0. The LOD and LOQ for UV absorbance measurements are dependent on the instrument and are three and six times, respectively, the standard deviation of ten replicate true blank measurements $[15,16]$.

Fluorescence emission from fluorescently labeled single stranded DNA (ssDNA) or dsDNA is used to estimate DNA concentration with fluorometry measurements [16]. Compared to concentration measurements based on UV spectroscopy, fluorometry is more specific for DNA because fluorescent labels have a higher binding affinity for DNA versus RNA. The limit of detection and quantification for fluorometric DNA concentration measurements is dependent on the fluorescent label and instrument used. A typical limit of detection for $200 \mu \mathrm{L}$ reactions measured using a plate reader is $2.5 \times 10^{-4} \mathrm{ng} / \mu \mathrm{L}$ [17].

Finally, qPCR is applied to measure target sequence copy number concentration. The copy number concentration is equated to DNA concentration based on within genome target sequence copy number and genome mass [18]. qPCR is the most specific method for DNA quantification because it only measures the targeted organism's DNA, however, qPCR only quantifies 
intact and accessible targets and does not estimate total DNA. The LOD for qPCR has been reported as 100 copies per reaction [19]. Fewer copies per reaction are detectable but the LOD is dependent on the repeatability of pipetting for low copy numbers. The LOQ is based on the qPCR assay range of linearity.

Several studies have compared DNA extraction methods suitability for microbial detection applications e.g. [20-25], however, valuable information regarding characterization of the DNA extraction products is absent from the extraction method comparison studies. For example DNA extract purity is frequently reported for the $A_{260} / A_{280}$ ratio but not the $A_{260} / A_{230}[20-22,25]$. Inclusion of the $A_{260} / A_{280}$ and $A_{260} / A_{230}$ ratio provides additional information about potential PCR inhibitors useful during method optimization. DNA extraction comparison study results are commonly presented in terms of the minimum number of detectable cells, the process LOD, for the different extraction methods and fail to use separate inhibition assays to evaluate extraction method performance. For example in a study by Dauphin et al. [21] the process LOD for DNA extracted using enzymatic lysis with magnetic bead purification was 500 CFUs and other extraction methods evaluated in the study had LODs of 5 CFUs. The difference in LOD could not be attributed to DNA yields as methods with LODs of 5 CFUs had similar yields to the enzymatic lysis and magnetic bead purification method ( $40 \mathrm{ng}$ ). Without results from a PCR inhibition assay there is no direct evidence that inhibitors caused the higher process LOD hindering method optimization. Additionally, independent reports of shearing are infrequently included in DNA extraction comparison studies although shearing can significantly lower the assay efficiency and inclusion would provide valuable information during methods development [26-28].

In order to show the benefits and value in the application of independent methods to characterize DNA extract quality and quantity, DNA was extracted from five cell types using six different extraction methods selected to represent major classes of extraction methods and cell types producing DNA varying in quantity and quality. The extraction methods included a traditional phenol chloroform extraction and five commercial kits utilizing different lysis and purification strategies. The five cell types include two Gram-negatives (Escherichia coli, and Burkholderia thailandensis), spores and vegetative cells from the Gram-positive Bacillus cereus, and the yeast Saccharomyces cerevisiae. Extracted DNAs were characterized using multiple methods frequently found in molecular biology laboratories; quantity, characterized by UV spectrometry, fluorometry, and qPCR, quality as defined by spectrometry, independent measures of PCR inhibition and shearing, and the benefits of the different characterization methods are discussed.

\section{Results}

DNA extracted from five different cell types using six different extraction methods (Table 1) was applied to DNA characterization methods as shown in Figure 1. DNA extract analysis is presented in terms of quality and quantity.

\section{DNA quality}

Extract quality was reported in terms of purity by UV spectroscopy, PCR inhibition using an independent qPCR assay, and intactness using gel electrophoresis.

UV absorbance ratios, $A_{280} / A_{260}$ and $A_{230} / A_{260}$, were used to evaluate DNA extract purity (Additional file 1: Table S1). Nanodrop-1000 performance was assessed with a dilution series of a control DNA sample (Human DNA Quantification standard SRM 2372 part A, Additional file 2: Figure S1). The reproducibility of the ratio values decreased for samples with measured concentrations less than $17.5 \mathrm{ng} / \mu \mathrm{L}$ (Additional file 2: Figure S1). Of the 108 DNA extracts examined, 47 had concentrations greater than $17.5 \mathrm{ng} / \mu \mathrm{L}$. All but one of the extracts (a $B$. cereus spore sample extracted using the reference method) had $\mathrm{A}_{260 /} \mathrm{A}_{280}$ ratios above 1.8. Extraction methods with a precipitation step as part of purification had the highest proportion of extracts with purity ratios within the accepted range of 1.8 to 2.0 for the $A_{260} / A_{280}$ ratio (grey box in Figure 2). A number of extracts had $A_{260} / A_{280}$ ratios above 2.0. A high proportion of samples extracted using the reference (14/17) and chemLysis $(7 / 8)$ methods as well as $S$. cerevisiae (7/9) extracts had $\mathrm{A}_{280} / \mathrm{A}_{260}$ ratios above 2.0 (Figure 2).

$\mathrm{A}_{260} / \mathrm{A}_{230}$ ratio, an indicator of RNA, phenol, salt, protein, and polysaccharide contamination, are presented in Figure 2. Most of the extracts (28 out of 47) had $\mathrm{A}_{260} /$ $\mathrm{A}_{230}$ ratios below 1.8, and 6 extracts had ratios above the accepted range (grey box in Figure 2). All extraction methods had low proportions of extracts within the accepted ratio. The reference method and precipB had purity ratios within or near the accepted ratios, $2.00 \pm$ 0.34 and $1.75 \pm 0.13$ (mean and standard deviation) respectively. A high proportion E. coli extracts, 9 out of 11 , were within the accepted ratio. Of the 6 extracts with $\mathrm{A}_{260} / \mathrm{A}_{230}$ ratios above 2.0 four were from S. cerevisiae.

Extracted DNA was assayed for PCR inhibitors using a detection independent inhibition assay, where a known number of exogenous DNA plasmids were added to the extracted DNA and evaluated using qPCR. The range in $\mathrm{C}_{\mathrm{t}}$ 's (threshold cycle) for each individual 96 well plate was less than 0.4 cycles, and the difference between the mean control $\mathrm{C}_{\mathrm{t}}$ for a plate and the inhibition reactions was less than 0.26 cycles (Figure 3). For inhibited samples the expected difference in $C_{t}$ values between the control and inhibition reactions is greater than 1 cycle, therefore no inhibition was observed. The mean $C_{t}$ 
Table 1 Extraction methods by application and processes

\begin{tabular}{|c|c|c|c|}
\hline Method $^{\mathrm{a}}$ & Intended sample type & Lysis method & Purification method \\
\hline Reference & General & Mechanical - Bead Beat & Phenol Chloroform \\
\hline PrecipB & Biofilm & Mechanical - Bead Beat & Precipitation and Silica Column \\
\hline MagBeads & General & Mechanical - Bead Beat & Magnetic Beads \\
\hline Precips & Soil & Mechanical - Bead Beat & Precipitation and Silica Column \\
\hline ChemLysis & Gram Negative & Chemical - Enzymatic & Silica Column \\
\hline PrecipG & General & Mechanical - Bead Beat & Precipitation and Silica Column \\
\hline
\end{tabular}

values for the $B$. cereus vegetative cells 96 well plate was 0.48 cycles greater than the mean for all other plates, this observed difference is due to run to run variation and not inhibition (Figure 3).

Finally, DNA shearing was evaluated using microfluidic gel electrophoresis. A cutoff value for quantitative analysis was set at 100 fragment concentration (FC), roughly 11 $\mathrm{ng} / \mu \mathrm{L}$ of DNA, as fluorescent reads below this cutoff were near the limit of detection preventing accurate size percentage calculations. Thirty-five samples had FC values above the cutoff with $93.5 \%(65.7 \%$ - 100\%, mean and percent range) of DNA larger than $1 \mathrm{~kb}$ and $1.0 \%(<1 \%$ 10.0\%) less than $300 \mathrm{bp}$ in size (Additional file 3: Figure S2). Slight shearing was observed for some of the vegetative cell samples extracted with methods using bead beating during the lysis step (Additional file 3: Figure S2). For example one $B$. thailandensis and one $B$. cereus sample extracted using precipB had broad peaks ranging in size from $450 \mathrm{bp}$ to over $17 \mathrm{~kb}$ with $77.5 \%$ and $81.1 \%$ of the DNA larger than $1 \mathrm{~kb}$ respectively (Additional file 3: Figure S2, precipB row). For extracts from vegetative cells the reference method, which included a bead beating lysis step, produced fragments less than 300 bp in size comprising $1.7 \%(0 \%-10.0 \%$, mean and range) of the extracted DNA (Additional file 3: Figure S2, Reference row).

\section{DNA quantity}

LOQs were established for the three different DNA concentration methods used to assess the quantity of DNA in extracts. LOQ for the Nanodrop based DNA measurements was set at $3.5 \mathrm{ng} / \mu \mathrm{L} ; 6$ times the standard deviation of 10 true negatives [15]. In comparison, the Qubit high sensitivity dsDNA LOQ was set at $0.25 \mathrm{ng} / \mu \mathrm{L}$ for this study, as the variability of replicate measurements increased for dilutions with measured concentrations below this value (Additional file 4: Figure S3). The LOQ for $\mathrm{qPCR}$ varies by assay and the LOQ is dependent on the qPCR efficiency, the number of copies of the target sequence within the organism's genome, and the organism's genome size. The qPCR LOQ for the assays in this study were; $5.72 \times 10^{-3} \mathrm{ng} / \mu \mathrm{L}$ for the $E$. coli, $2.66 \times 10^{-3}$ $\mathrm{ng} / \mu \mathrm{L}$, for B. cereus, $3.78 \times 10^{-3} \mathrm{ng} / \mu \mathrm{L}$ for B. thailandensis, and $7.67 \times 10^{-4} \mathrm{ng} / \mu \mathrm{L}$ for $S$. cerevisiae. The actual copy

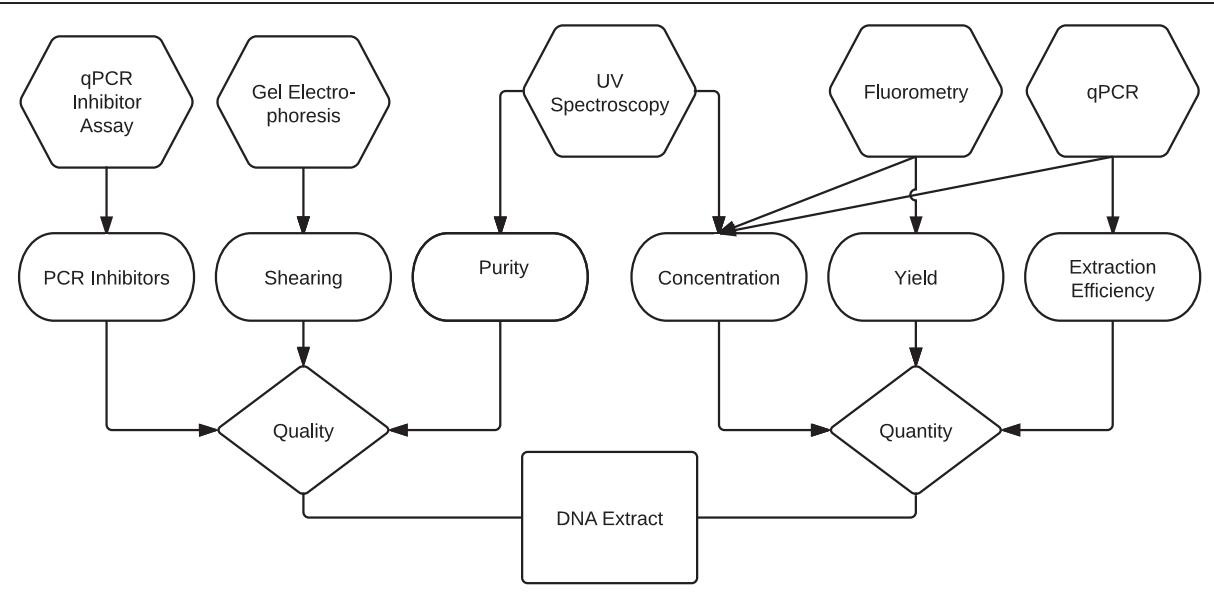

Figure 1 Flowchart of measurement methods used to evaluate the extracted DNA quantity and quality. Parameters, characteristics, and measurement methods are indicated in diamond, oval, and hexagon blocks, respectively. 


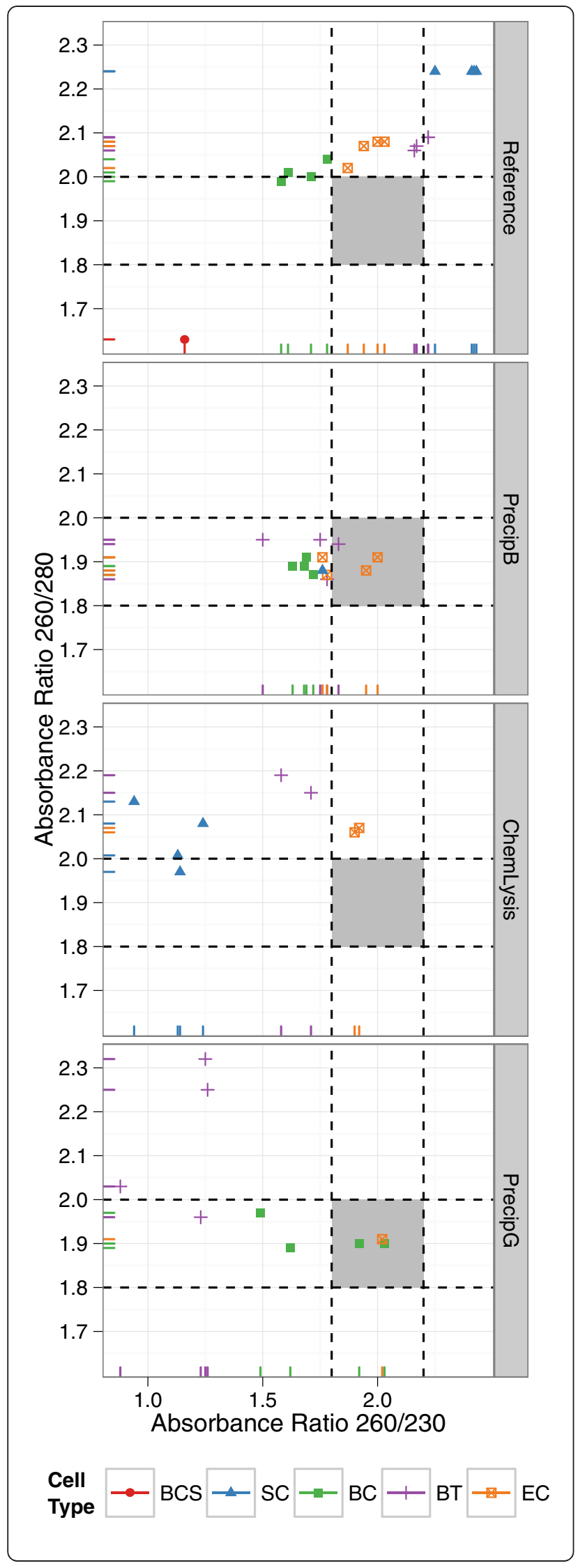

Figure 2 Scatter plot DNA extract purity $\left(A_{260} / A_{280} \mathrm{~nm}\right.$ vs. $\left.A_{\mathbf{2 6 0}} / A_{\mathbf{2 3 0}} \mathbf{n m}\right)$. Only samples with DNA concentrations greater than $17.5 \mathrm{ng} / \mu \mathrm{L}$ were included in the analysis. Graphs are separated by extraction method. Cell types are indicated by the data point shape, color, and rug plot color: $B$. cereus spores $(n=1$ extracts), Red $\bullet$ S. cerevisiae ( $n=9$ extracts), blue $\boldsymbol{\Lambda}, B$. cereus vegetative ( $n=12$ extracts), green $\mathbf{m}, B$. thailandensis $(n=15$ extracts), purple + , and E. coli $(n=11$ extracts), yellow $\otimes$. Dotted lines indicate the upper limits of community accepted purity ratios; light grey areas show the lower limits of community accepted purity ratios.

number LOQ for the three assays ranged from 1000 to 248 copies per reaction. A number of samples were below the limit of quantification of the Nanodrop $(n=27)$ and Qubit HS assay $(n=15)$. Three of the 108 samples were below the qPCR assays LOQ.

Overall DNA concentration ranged from $1502.2 \mathrm{ng} / \mu \mathrm{L}$ to below the LOQ, depending on characterization and extraction methods (Table 2). The DNA concentration measurements made using the Nanodrop were statistically greater than the other two (for example measurement methods for the reference $(\mathrm{p}<0.00)$, chemLysis $(\mathrm{p}<0.00)$, and precipS $(\mathrm{p}<0.03)$, (Table 2$)$.

Calculation of extraction efficiencies using qPCR concentration values allow for a more direct comparison with the literature where it is common to present extraction methods in terms of the overall process efficiency. Extraction efficiencies varied significantly $(\mathrm{p}<$ 0.05 ) by both cell type and extraction method, with efficiencies ranging from less than $0.0001 \%$ to over $100 \%$ (Figure 4). Extraction efficiencies in general were higher for the two Gram-negative organisms than the hard to lyse cells types; yeast, spores, and Gram-positive. For example for extractions using chemical lysis the extraction efficiency for the hard to lyse cell types was less than $1 \%$ and statistically lower $(\mathrm{p}<0.05)$ than the Gramnegative, $B$. thailandensis and $E$. coli with mean extraction efficiencies of $27 \%$ and $86 \%$ respectively. The three precip extraction methods all used bead beating for lysis with precipitation and silica spin columns for purification but had different ranges in extraction efficiency (Figure 4C,D,F).

\section{Discussion}

The purpose of this work was to evaluate commonly used DNA characterization methods for applicability to inform the assay developer of DNA extraction method performance. The results are discussed in terms of DNA extract quality and quantity.

\section{DNA quality}

DNA extract purity is of interests in terms of how contaminants will affect downstream assay performance. UV spectroscopy provides an indicator for different 

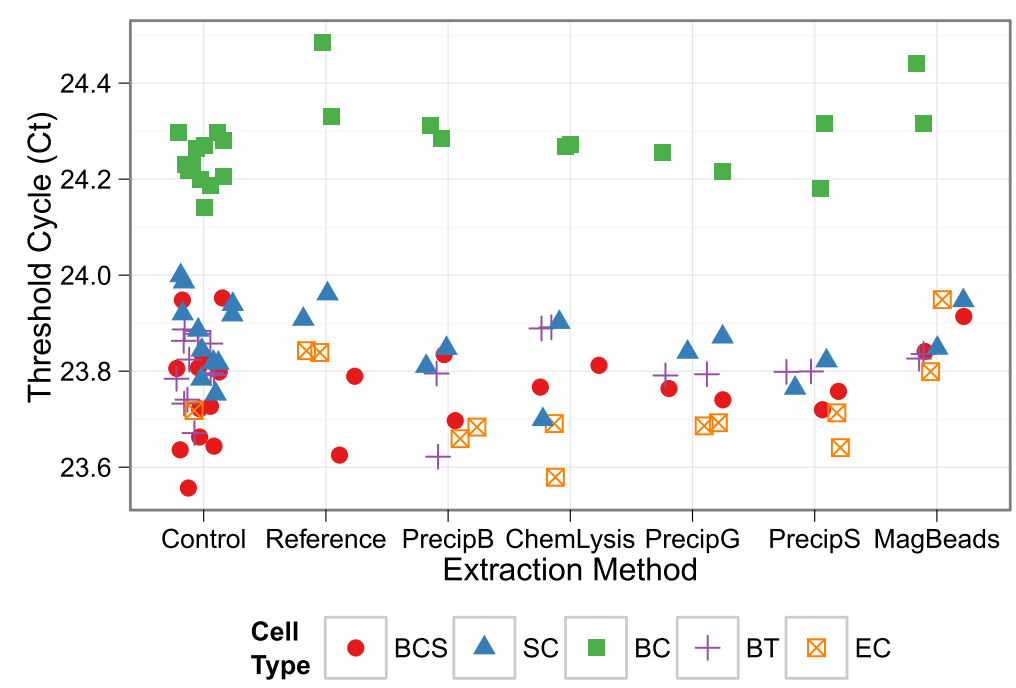

Figure 3 Evaluation of PCR inhibition for extracts from five cell types. Data points represent the median cycle threshold (Ct) values for $\mathrm{n}=3$ replicates. Shape and color indicate the source cell type, B. cereus (spore), red $\bullet$, S. cerevisiae, blue $\boldsymbol{\Lambda}$, B. cereus, green $\mathbf{\square}, B$. thailandensis, purple + , E. coli, orange $\otimes$, of the extracted DNA, respectively.

types of extract contaminants such as proteins, polysaccharides, and RNA [7]. PCR inhibition assays indicate whether contaminants will adversely affect the qPCR detection assay [29]. Purity ratios, obtained using UV spectroscopy, were outside the accepted range (1.8 to 2.0 for $\mathrm{A}_{260} / \mathrm{A}_{280}$ and 1.8 to 2.2 for $\mathrm{A}_{260} / \mathrm{A}_{230}$ ) for most extracts but no PCR inhibition was observed.

High $\mathrm{A}_{260} / \mathrm{A}_{280}$ absorbance ratios, indicating RNA coextraction [30,31], were observed for 25 of the 47 samples with sufficient DNA concentration for reliable purity ratio measurement. The reference method had the highest proportion of extracts with $\mathrm{A}_{260} / \mathrm{A}_{280}$ ratios above 2.0, most likely due to RNA co-extraction with acidic phenol (phenol chloroform had pH of 5.2) [5]. A high proportion of the $S$. cerevisiae extracts also had high $A_{260} / A_{280}$, the reason for the suspected RNA contamination is unknown but possibly due to the difference in mRNA decay between prokaryotes and eukaryotes [32]. RNA in DNA extracts does not interfere with downstream applications but does cause overestimation of UV spectroscopy determined DNA concentrations [7].

Humic acids, proteins and polysaccharides, indicated by low $\mathrm{A}_{260} / \mathrm{A}_{230}$, adversely affect PCR amplification kinetics $[7,8,33,34]$. A majority of the extracts in this study had low $\mathrm{A}_{260} / \mathrm{A}_{230}$ purity ratios. The contaminants are likely polysaccharides as humic acids are found in soil and sediment environmental samples and not associated with cells $[35,36]$ and protein contamination would have caused low $\mathrm{A}_{260} / \mathrm{A}_{280}$ ratios which were not observed [7]. Extraction methods are often optimized to enhance the removal of polysaccharides for example including the use of the surfactant ctyl trimethylammonium bromide or precipitation with high salt concentrations [36,37]. Similarly, the precipitation purification step included in three of the extraction methods reduced DNA contaminants as indicated by the higher proportion of extracts with purity ratios within the accepted range compared to the other extraction methods (Figure 2). For detection of

Table 2 DNA concentration $\mathrm{ng} / \mu \mathrm{L}$, presented as median (maximum - minimum) measured using three different measurement methods

\begin{tabular}{lccc}
\hline Extraction method & UV spectroscopy & qPCR & Fluorometry \\
\hline Reference & $524.4\left(1502.2-<\mathrm{LOQ}^{*}\right)$ & $144.2(487.7-0.02)$ & $84.2(460.0-<\mathrm{LOQ})$ \\
PrecipB & $61.1(178.3-3.8)$ & $101.5(149.4-0.00)$ & $51.8(178.4-3.8)$ \\
ChemLysis & $16.5(110.2-<\mathrm{LOQ})$ & $2.1(47.7-0.19)$ & $2.2(55.2-<\mathrm{LOQ})$ \\
PrecipG & $14.9(44.4-<\mathrm{LOQ})$ & $8.4(94.5-0.17)$ & $6.2(29.6-<\mathrm{LOQ})$ \\
PrecipS & $4.0(12.0-<\mathrm{LOQ})$ & $1.5(6.1-0.01)$ & $1.4(9.5-<\mathrm{LOQ})$ \\
MagBeads & $4.3(7.6-<\mathrm{LOQ})$ & $0.2(1.3-<\mathrm{LOQ})$ & $0.4(2.4-<\mathrm{LOQ})$ \\
\hline
\end{tabular}

" below the method limit of quantification (LOQ). 

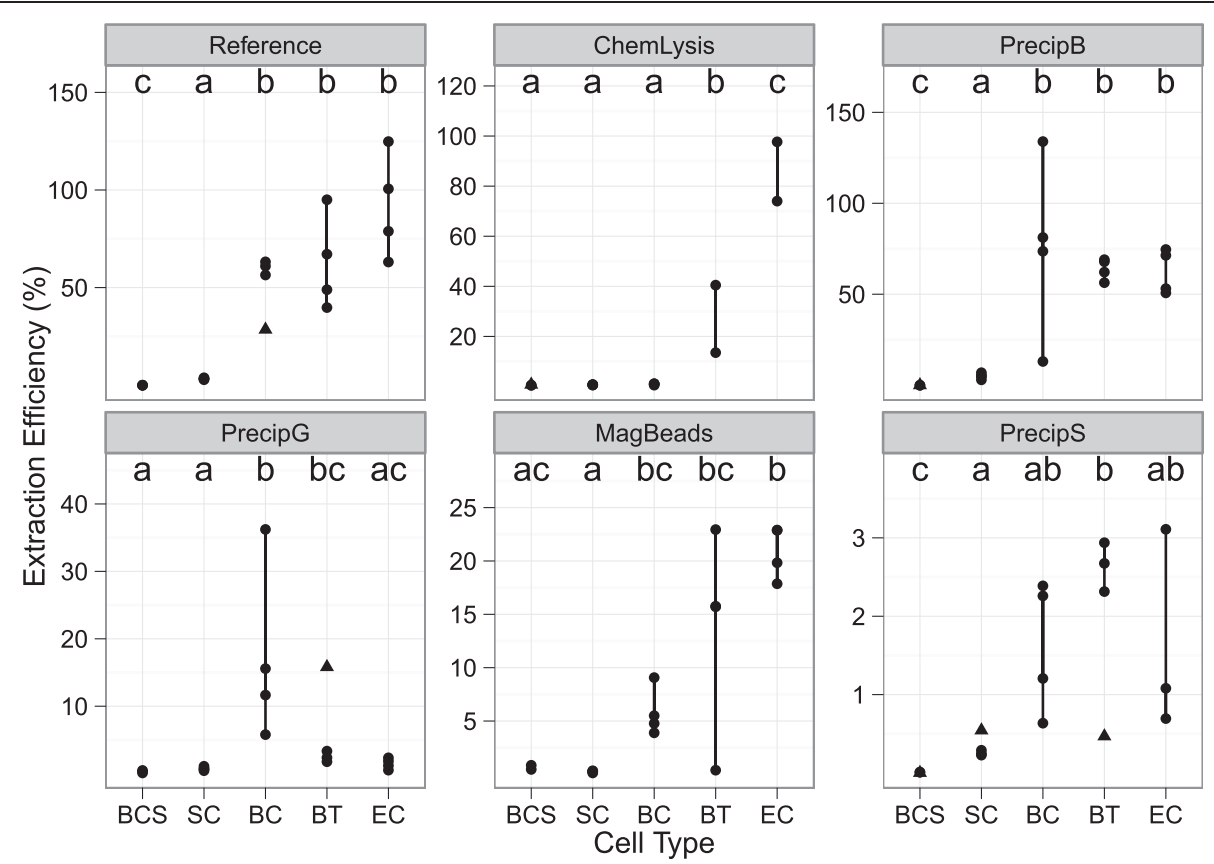

Figure 4 DNA extraction efficiency as a function of cell type quantified by qPCR. Cell types are labeled as follows: B. cereus (spore), BCS, S. cerevisiae, SC, B. cereus, BC, B. thailandensis, BT, E. coli, EC. Vertical lines indicate the dispersion of the data; replicate outliers are indicated as $\boldsymbol{\Delta}$ data points. Black letters $(a, b, c)$ indicate statistical differences within each plot, based on a Tukey's HSD test with $p<0.05$, when the outliers were excluded in the analysis. Plots are grouped by extraction method. Scales are independent for each graph due to the large range in responses.

pathogens in samples that are rich in polysaccharides it is essential to optimize the extraction method for their removal $[30,37]$.

The primary limitation to UV spectroscopic DNA purity measurements is that the measurement only provides indicators for different types of contaminants and no information about the effect of these contaminants on downstream applications. Additionally, purity assays are sometimes used when specific contaminants are of interest, such as measuring UV absorbance of a sample at $320 \mathrm{~nm}$ for humic acid detection [38]. A second limitation to the method is the required sample concentration, samples with measured concentrations less than $17.5 \mathrm{ng} / \mu \mathrm{L}$ were found to have unreliable purity ratios and purity measurements were only available for half of the extracts characterized in the study.

Few reports explore the link between extract quality and PCR assay performance and/or optimization. PCR inhibitors are often associated with the sample matrix, including blood, food, water and soil [36]. For example, polysaccharides are known to interfere with downstream detection of plant diseases and pathogen contamination in food and water [36]. Although no inhibitors were expected because pure cultures were applied in this study, it is important to run inhibition assays to ensure the extracted purity is suitable for downstream applications. PCR inhibitors can lead to false negatives or underestimation of the quantity of a biological agent. qPCR assay susceptibility to inhibition varies by polymerase, primer regions, and target sequence [39-41]. Even though two different assays, one for inhibition and one for DNA quantification by qPCR, were used in this study and no inhibition was observed it is not likely that inhibitors were not detected as Qubit and qPCR measurements were in agreement (Table 2).

DNA fragmentation can decrease qPCR efficiency or cause the reaction to fail completely $[28,42]$ resulting in higher process LODs. Assays requiring larger target sequences are more likely adversely affected by shearing $[27,28]$. When DNA extracts are evaluated for shearing it is commonly performed using standard agarose gel electrophoresis $[26,43,44]$. The use of microfluidic gel electrophoresis allows for a lower limit of detection (11 ng per sample compared to $20 \mathrm{ng}$ per band) and semi-quantitative shearing analysis compared to standard gel electrophoresis [45]. The ideal target length for qPCR is $50 \mathrm{bp}-200 \mathrm{bp}$ [46]. Overall $1.0 \%(0 \%-10.0 \%$, mean and range) of the extracted DNA was less than $300 \mathrm{bp}$ and therefore the degree of shearing observed for the DNA extracts did not impact qPCR performance. Slight shearing was observed for a number of the vegetative cell samples extracted with the bead beating method. Bead beating causes shearing but as observed in 
this study the degree of shearing varies and does not adversely affect most PCR applications using large quantities of genomic DNA $[43,47]$.

\section{DNA quantity}

Accurate DNA quantity measures are critical to assay optimization as losses in DNA due to extraction procedures contribute to a reduction in overall detection assay performance $[25,38]$. While more accurate DNA concentration measurement methods are available including digital PCR and phosphorus elemental analysis [12-14] the methods used in this study represent those that are commonly used in molecular and diagnostic laboratories. The three DNA concentration measurement methods used in this study were UV spectroscopy, spectrofluorometry, and qPCR.

Each of the concentration methods used has different assumptions, and limitations. For example UV spectroscopy based concentration measurements requires two assumptions. First, DNA is the only molecule in the extract that absorbs light at $260 \mathrm{~nm}$ and second, the DNA is all double-stranded. The UV spectroscopy DNA concentration measurements were statistically higher than the other two measurement methods (Table 2). The $\mathrm{A}_{260} / \mathrm{A}_{280}$ and $\mathrm{A}_{260} / \mathrm{A}_{230}$ absorbance ratios above the acceptable range observed for a number of extracts indicated that co-extracted RNA caused the $\mathrm{A}_{260}$ measurement to overestimate DNA concentration (Table 2). Absorbance based DNA concentration measurements commonly overestimate DNA concentrations for environmental samples due to contaminants from the sample matrix [48]. Accuracy of absorbance based DNA concentration measurements is dependent on sample purity $[48,49]$. For extracts known to contain contaminants such as RNA and protein other DNA concentration measurement methods such as spectrofluorometry and qPCR are more suitable than UV spectroscopy. The primary advantage of UV spectroscopy is the availability of microvolume instruments that are faster, easy to use, and requires less sample volume [48].

The Qubit and other bench top fluorometers allow for relatively fast DNA concentration measurements that are not as adversely affected by DNA contaminants as UV spectroscopy [45]. The concentration measurements for $\mathrm{qPCR}$ and Qubit were in agreement (Table 2). A number of DNA extracts $(n=15)$ were below the identified method LOQ of $0.25 \mathrm{ng} / \mu \mathrm{L}$ and therefore the measurement method was not suitable for hard to lyse cells that had extracts with low concentration (Table 2, Additional file 4: Figure S3). Fluorometric DNA concentration measurements do not measure ssDNA in the sample and can lead to DNA concentration underestimation [45]. The accuracy of the fluorometric DNA concentration measurements is dependent on the accuracy of the DNA standards used [19]. Ideally the DNA concentration standard used should have a certified concentration that is traceable to the SI and has a published uncertainty value [19]. The standards in DNA concentration assay kits do not always meet this requirement and the concentration measurements should be evaluated with this in mind [50]. The advantage of using fluorometric DNA concentration measurement methods compared to qPCR is that no additional assay development is required for individual organisms.

Quantitative PCR (qPCR) was the third method used to measure DNA concentration. DNA concentration measurements made using $\mathrm{qPCR}$ assume the number of within genome DNA sequence target copies is known and constant and that whole genomes are extracted [18]. qPCR had the lowest observed limit of quantification $\left(\sim 10^{-3} \mathrm{ng} / \mu \mathrm{L}\right.$ depending on the assay) and the fewest number of samples with concentrations below the method LOQ $(n=3)$. The primary limitation to using qPCR for measuring DNA concentration is that; method development, validation, and execution are significantly more time intensive and costly than either of the two other methods. However, qPCR is the only measurement method that measures the DNA concentration of a specific organism in a mixed sample (e.g. detection of pathogens in food or tissue samples). As with fluorometric DNA concentration measurements qPCR concentration measurements require the use of a standard. The standard used can be a major source of qPCR measurement uncertainty [19]. No standard reference materials are available for the GPCR assays used in this study and the associated uncertainty of the standards used in this study was unknown.

Finally, extraction efficiencies ranged by method and even varied for the three methods that used precipitation and silica spin columns for purification and bead beating for lysis indicating that extraction efficiency was dependent on more than the fundamental properties of the extraction methods. It is important to note when discussing reported extraction efficiencies that quantity and quality are factors of the kits intended use as there is a tradeoff between the two. For example the magBeads extraction method was designed for use in field applications with limited resources and user experience. While the concentration of the resulting DNA was low, the extraction efficiency was comparable to the other extraction methods (Table 3, Figure 4). Similarly, the lysis step for the chemLysis method was optimized for Gram-negative bacteria as evident with the higher extraction efficiency for B. thailandensis and E. coli compared to the other cell types. Soils are rich in PCR inhibiting humic acids [36] and the precipS extraction method, optimized for extracting DNA from soils, included a purification step to remove humic acids. Additional, steps may have resulted in 
Table 3 DNA primers used in quantity qPCR assays

\begin{tabular}{|c|c|c|c|c|c|c|}
\hline Organism & Gene target (amplicon size) $^{a}$ & Name & Sequence & Con $^{b}$ & $\mathrm{AE}^{\mathrm{c}}$ & Ref. \\
\hline \multirow[t]{2}{*}{ E. coli } & lacZ (70) & lacZF1 & CCT GAG GCC GAT ACT GTC GT & 3 & 0.99 & [52] \\
\hline & & lacZR1 & TTG GTG TAG ATG GGC GCA T & 3 & & \\
\hline \multirow[t]{2}{*}{ B. thailandensis } & flic (62) & flicF1 & AGC AGA TCT CGG AAG TGA ACC & 2 & 0.92 & This study \\
\hline & & fliCR1 & GAG GAT GTT CTT GCC GTT GT & 2 & & \\
\hline \multirow[t]{2}{*}{ B. cereus } & pc-p/c (144) & PCER-F & GGA TTC ATG GAG CGG CAG TA & 3 & 0.95 & [53] \\
\hline & & PCER-3R & GCT TAC CTG TCA TTG GTG TAA CTT CA & 2 & & \\
\hline \multirow[t]{2}{*}{ S. cerevisiae } & $26 S^{d}(124)$ & YEAST-F & GAG TCG AGT TGT TTG GGA ATG C & 3 & 0.91 & {$[54]$} \\
\hline & & YEST-R & TCT CTT TCC AAA GTT CTT TTC ATC TाT & 2 & & \\
\hline
\end{tabular}

\footnotetext{
${ }^{a}$ Amplicon size in base pairs.

b Optimized primer concentration $(\mu \mathrm{M})$.

c Amplification Efficiency, calculated using the slope of the standard curve.

${ }^{d}$ Assay targeted the D1/D2 variable region of $26 \mathrm{~S}$.
}

loss of genomic DNA. A range of different size beads are used in the bead beating step of precipB which may aide in lysis of different cell types resulting in the statistically similar extraction efficiencies between all vegetative cell types not observed for the other extraction methods (Figure 4). Analysis of DNA yields using different size beads found that higher yields for hard to lyse Mycobacteria were obtained using smaller sized beads $(0.1 \mathrm{~mm}$ vs $0.5 \mathrm{~mm})$, but no studies have empirically evaluated lysis efficiency for different cell types using different size beads [51]. For precipG quantity was sacrificed as the quantity of the intended sample type, microbial cultures, is not limited.

\section{Conclusions}

During optimization of detection assays and determining which DNA extraction method to use, downstream application requirements and common sources of downstream application inhibitors [55-57] will dictate what methods are chosen to characterize DNA extract quality and quantity. When optimizing for true unknowns it is advantageous to use extraction methods that are optimal for hard-to-lyse cells. The limited number of cell types and extraction methods evaluated here were not intended to be exhaustive or to guide extraction method selection but rather to present the limitations and advantages of different extract characterization methods. The use of only a single sample type was a limitation of the study and additional sample types would have better challenged the inhibition assay. Along the same lines the use of more intense mechanical lysis procedures such as longer bead beating steps or sonication may have produced DNA extracts that better challenged the shearing characterization assay. More importantly, the study provides a procedural model for assessing DNA extract quantity and quality that can be applied when evaluating extracts for other microbiology fields such as microbial ecology marker gene studies and shotgun metagenomics.
The extract characterization methods presented here can serve as a starting point for the development of a standard procedure for evaluating DNA extract quality and quantity for universal applications in the study of microbial systems.

\section{Methods}

\section{Culture preparation and cell enumeration}

DNA was extracted from five cell types: the Gram negative Burkholderia thailandensis (ATCC700388) and Escherichia coli 0157:H7 non-toxic strain (ATCC700728), Gram positive Bacillus cereus vegetative cells and spores (ATCC10987), and the eukaryote Saccharomyces cerevisiae (ATCC 204516). Vegetative cell types were cultured in $20 \mathrm{~mL}$ of Luria-Bertani (LB) broth with shaking (30 $\mathrm{rpm})$ at $30^{\circ} \mathrm{C}$ overnight. S. cerevisiae was grown in potato dextrose broth overnight at $37^{\circ} \mathrm{C}$ with shaking. Cultures were washed and stored in $1 \mathrm{~mL}$ aliquots at $-80^{\circ} \mathrm{C}$ until extraction or enumeration. Aliquots were stored in either phosphate buffered saline with $0.04 \%$ Tween 80 (PBST) or PBST with $10 \%$ glycerol (PBST-gly). B. cereus spores were prepared using the procedure described in Da Silva et al. [58], using PGSM sporulation media and stored in $47.5 \%$ ethanol at $4{ }^{\circ} \mathrm{C}$. Sporulation media was comprised of $1.5 \%$ agar, $7.5 \mathrm{~g}$ nutrient broth (Difco Bacto-peptone; VGD, Inc.), $1 \mathrm{~g}$ glucose, $3.4 \mathrm{~g} \mathrm{KH}_{2} \mathrm{PO}_{4}$, and $4.35 \mathrm{~g} \mathrm{~K}_{2} \mathrm{HPO}_{4}$ in $1 \mathrm{~L}$ sterile deionized water. After the media was autoclaved, $5 \mathrm{~mL}$ of filter sterilized $\mathrm{CaCl}_{2}(0.0366 \mathrm{~g} / \mathrm{mL})$ and a salt solution $\left(0.0246 \mathrm{~g} / \mathrm{mL} \mathrm{MgSO}_{4}, 4 \times 10^{-4} \mathrm{~g} / \mathrm{mL} \mathrm{MnSO}_{4}\right.$, $0.0028 \mathrm{ZnSO}_{4}, 0.004 \mathrm{~g} / \mathrm{mL} \mathrm{FeSO}_{4}$ ) was added.

All cultures were enumerated using a Petroff-Hausser Counting Chamber (Huasser Scientific, Horsham, PA, USA). Samples were diluted 10 fold to a countable concentration in PBST, and triplicate samples were visualized and enumerated using phase contrast microscopy with an Olympus BX51 microscope. 


\section{DNA extraction}

DNA was extracted from culture preparations $\left(1-5 \times 10^{9}\right.$ cells $/ \mathrm{mL}$ ) using six extraction methods utilizing different lysis and purification procedures (Table 1). Extraction methods were chosen based on their ability to produce DNA extracts with a range of quantity and quality characteristics that represented general classes of lysis and purification methods. Four extractions were performed for all cell types except for B. cereus spores, which were extracted in triplicate for each of the extraction methods. Due to limited sample size only two extractions were performed using the chemLysis method for E. coli and $B$. thailandensis, and three E. coli samples were extracted with precipS. The manufactures' protocols for all commercial extraction methods were followed excluding using the specified sample type for precipS and precipB methods and no RNAase step was performed for the chemLysis extraction method. For the chemLysis extraction method the manufacture's Gram-negative lysis protocol was used. Bead beating steps were performed using the Vortex-Genie 2 (MoBio Laboratories, Inc. California, USA) set at the maximum speed with a MoBio vortex adapter. Extracted DNA was stored at $-20^{\circ} \mathrm{C}$ until DNA quantity and quality analysis.

A non-commercial phenol-chloroform based protocol was used as a reference method [9]. Culture aliquots were pelleted by centrifugation $(13,000 \times g$ for $3 \mathrm{~min})$ and resuspended in $500 \mu \mathrm{L} 1 \times$ TE buffer (Tris-EDTA, pH 8, Fisher Bioreagents, New Jersey, USA). The re-suspended pellet was transferred to a $2 \mathrm{~mL}$ tube with screw caps (BioSpec Products, Inc. Oklahoma, USA) with $0.8 \mathrm{~g}$ zirconia/silica beads (BioSpec Products, Inc.). Tubes were bead beaten for $20 \mathrm{~min}$ then centrifuged for $30 \mathrm{sec}$ at $10,000 \times g$. The supernatant was transferred to a new tube to which $800 \mu \mathrm{L}$ phenol chloroform 1:1 (MP Biochemicals, Ohio, USA) was added then vortexed for $30 \mathrm{~s}$ to mix. Tubes were centrifuged at $10,000 \times g$ for $10 \mathrm{~min}$ and the aqueous phase was transferred to a new tube. Next, $500 \mu \mathrm{L}$ chloroform isoamyl alcohol 24:1 (Acros Organics, New Jersey, USA) was added and the solution was vortexed again for $30 \mathrm{~s}$. Aqueous and polar phases were separated by centrifugation $(10,000 \times g$ for $10 \mathrm{~min}$ ). Aqueous phase was transferred to a new tube to which $1 \mathrm{~mL}$ of absolute ethanol and $50 \mu \mathrm{L}$ of $3 \mathrm{M}$ sodium acetate was added. Tubes were vortexed briefly then incubated at $-20^{\circ} \mathrm{C}$ for $30 \mathrm{~min}$. DNA was pelleted by centrifugation $(13,000 \times g, 10 \mathrm{~min})$ and washed with $70 \%$ ethanol. The washed pellet was allowed to air dry for 30 min then re-suspended in $50 \mu \mathrm{L}$ of $0.1 \times \mathrm{TE}$ and stored at $-20^{\circ} \mathrm{C}$.

\section{DNA quality}

DNA extract quality was reported based on independent measurements of purity and PCR inhibition DNA (Figure 1). The DNA UV absorbance measured using a
Nanodrop-ND1000 (Thermo Fisher Scientific, Waltham, MA) provides an assessment of contaminants (polysaccharides and proteins). The absorbance ratios for $\mathrm{A}_{280} /$ $A_{260}$ and $A_{260} / A_{230}$ were determined for $2 \mu \mathrm{L}$ samples using ND-1000 V3.8.1 software (Thermo Fisher Scientific, Waltham, MA). Additionally, a dilution series of a control DNA (Human DNA quantification standard SRM 2372 part A, National Institute of Standards and Technology, Gaithersburg, MD) was used to assess the precision of the purity ratio measurements for different DNA concentrations. The SRM 2372 at the time of certification was double stranded. Overtime an unknown proportion of the DNA standard has become single stranded. Due to the change in strandedness of the DNA standard the certified UV absorbance values are longer representative of the standard and cannot be used in assessing instrument performance and measurement accuracy.

\section{PCR inhibition assay}

The presence of PCR inhibitors in DNA extracts was determined using an inhibition control assay. Reactions were run on the ABI 7900 HT Real Time PCR System following manufacturers recommended thermocycling profile. Inhibition reactions of $20 \mu \mathrm{L}$ included $1 \times$ TaqMan ${ }^{\circledR}$ Environmental Master Mix 2.0 (Life Technologies, Grand Island, NY), 1× ERCC-00095 assay (Ac03459926_a1, Life Technologies, Grand Island, NY), 750 copies of ERCC-00095 plasmid (SRM 2374 candidate material with a certified DNA sequence; National Institute of Standards and Technology, Gaithersburg, $\mathrm{MD})$, and $2 \mu \mathrm{L}$ of extracted DNA being assayed for PCR inhibitors. Duplicate extractions for each cell type and extraction method combination were evaluated for the presence of inhibitors; excluding $B$. thailandensis reference method extractions, due to limited DNA. Cell types were run independently on separate 96 well. Twelve plasmid controls reactions, where no extracted DNA was added, were included in each run, excluding the $E$. coli cell type, to evaluate within and between run variability. The SDS v2.4 software (Life Technologies, Grand Island, NY) with default settings was used to calculate the threshold cycle $\left(C_{t}\right)$.

\section{DNA shearing}

DNA shearing was evaluated by microfluidic gel electrophoresis with the Agilent Bioanalyzer 2100 and DNA 12000 assay (Agilent Technologies, Inc. Santa Clara, CA) according to manufacturer's instructions. The Agilent Bioanalyzer measures fluorescence intensity emitted by fluorescently labeled dsDNA as it passes through the detector and results are electropherogram plots. Time to detect and fluorescence are proportional to DNA size and concentration. The total amount of DNA detected, the percentage of DNA $>300 \mathrm{bp}$ and $<1 \mathrm{~kb}$ was 
calculated in $\mathrm{R}$ (version 2.15.0) as the area under the electropherogram using the trapezoid method (ROC package), with area under the curve $(\mathrm{FU} \times \mathrm{s})$, presented as fragment concentration (FC).

\section{DNA quantity}

DNA concentration limit of detection and quantification

DNA quantity was measured using three different methods; UV spectroscopy, spectrofluometry, and quantitative PCR (qPCR) (Figure 1). The UV spectrophotometer, Nanodrop-ND1000 (Thermo Fisher Scientific, Waltham, MA), was used to measure DNA concentration, wherein 1 optical density at $260 \mathrm{~nm}$ is equivalent to $50 \mathrm{ng} / \mu \mathrm{L}$ of dsDNA [9]. The limit of quantification for Nanodrop measurements was defined as 6 times the standard deviation of 10 true negative replicates [15]. Spectrofluorometric DNA concentration measurements were made using Qubit (Invitrogen, Carlsbad, CA). Qubit assays were performed following the manufacture's protocol. The Qubit broad range assays was used to measure DNA concentration, for samples with concentrations less than $1 \mathrm{ng} / \mu \mathrm{L}$ the Qubit high sensitivity assay was used. The standard deviation of true negatives principle used to determine the LOQ for the Nanodrop is not applicable to Qubit measurements as DNA concentrations out of range of the standard curve are stated as such by the instrument and therefore no values are provided for true negatives [15]. The LOQ for the Qubit high sensitivity assay was determined using a dilution series of a control DNA (Human DNA Quantitation Standard SRM 2372 part A). Genomic DNA copy number was determined using organism specific qPCR assays (Table 3 ). qPCR LOQ $(q L O Q, n g / \mu \mathrm{L})$ values were determined by first calculating the genome mass (GM, ng/ genome) based on the size of the organism's genome (GS, $\mathrm{bp} /$ genome) and the established mass to bp constant of $0.978 \times 10^{12} \mathrm{bp} / \mathrm{ng}$ (Eq. 1) [18,19,52].

$$
G M=\frac{G S}{0.978 \times 10^{12}}
$$

$q L O Q(\mathrm{ng} / \mu \mathrm{L})$ values were then determined based on the plasmid copy number for the lowest dilution in the standard curve $(p L D$, copies $/ \mu \mathrm{L})$ the number of target sequences per genome ( $\mathrm{CNg}$, copies/ genome), and the mass of the organisms genome ( $G M, \mathrm{ng} /$ genome) which was calculated using equation 2 .

$$
q L O Q=\frac{(p L D \times G M)}{C N g}
$$

\section{qPCR concentration assays}

For the qPCR assays, primer sequences were obtained from the literature except the sequences obtained for the
Burkholderia thailandensis assay, which were designed using Primer3Plus (www.bioinformatics.nl) to target the $\mathrm{fliC}$ gene, which was used in previous studies to quantify Burkholderia species [59]. Primer specificity was verified in-silico using Primer-BLAST (www.blast.ncbi.nlm.nih. gov). Standard curves of plasmids containing PCR amplified target sequences were used for absolute quantification. Plasmids containing PCR target sequences were produced using the pGEM-T Easy Vector System (Promega Corp., Madison, WI) according to manufacturer's protocol, purified using the QIAprep Spin Miniprep Kit (Qiagen Inc., Valencia, CA), and linearized by Fast Digest SacI restriction digest (Fermentas Inc., Glen Bernie, MD). Plasmid DNA concentration was determined using the Qubit Broad Range Assay.

qPCR reactions were run on the 7900 HT Real Time PCR System (Life Technologies, Grand Island, NY). Samples, standard curves, and no template controls were run in triplicate with $1 \times$ Power SYBR ${ }^{\circledR}$ Green PCR Master Mix (Life Technologies, Grand Island, NY), primers at optimized concentrations, and molecular grade nuclease-free water (Life Technologies, Grand Island, $\mathrm{NY}$ ) was added for a final volume of $20 \mu \mathrm{L}$. Between $1 \mathrm{ng}$ and $10 \mathrm{ng}$ of extracted DNA was added to sample reactions, molecular grade water was added to the no template control reactions in place of extracted DNA, and a 10 fold plasmid dilution series was added to standard curve reactions. Primer concentrations were optimized according to Nolan et al. [46]. Reaction specificity was verified using melt curve analysis, and $\mathrm{r}^{2}$ values were determined using SDS v2.4 software (Life Technologies, Grand Island, NY) with default settings. $B$. cereus and S. cerevisiae samples were run on two 96 well plates, inter-run calibrators (IRCs) were used to normalize for run-to-run variation [60].

\section{qPCR concentration values}

qPCR DNA concentration was calculated first by determining the concentration of genome equivalents (cGE, genome equivalents $(G E) / \mu \mathrm{L}$, Eq. 3) in the extract based on the median of triplicate target sequence copy number concentrations in the extract determined using qPCR $(q C N$, copies $/ \mu \mathrm{L})$ and the number of target sequences per genome ( $\mathrm{CNg}$, copies/genome). Except for two of the B. cereus spores PrecipB extracts, where the average of duplicate qPCRs were used to determine the quantity values due to one of the triplicate reactions failing.

$$
c G E=\frac{q C N}{C N g}
$$

The qPCR DNA concentration calculations were based on the organism's genome mass (GM, ng/genome, Eq. 1) 
and the concentration of genome equivalents $(c G E, \mathrm{GE} /$ $\mu \mathrm{L})$ (Eq. 4) $[18,61]$.

$$
[D N A]=c G E \times G M
$$

The three DNA concentration measurement methods were compared for each extraction method using a oneway ANOVA with Tukey's HSD test for post hoc pair wise comparisons.

Extraction efficiency was calculated (Eq. 5) as the ratio of qPCR yield ( $q Y$, GE, Eq. 6) to the total number of cells extracted ( $C E$, cells, Eq. 7), which was the product of the culture concentration $(C C$, cells $/ \mathrm{mL})$ and the volume of cells extracted $(V E, \mathrm{~mL})$.

$$
\begin{aligned}
& E E=q Y / C E \\
& q Y=c G E \times E V \\
& C E=C C \times V E
\end{aligned}
$$

Replicate extraction efficiency outliers were detected using Grubb's test, as implemented in R (outliers package) on extractions with more than two replicates. A series of one-way ANOVAs and post hoc pairwise comparison tests, Tukey's HSD, were run in R on log transformed qPCR extraction efficiencies values for each extraction method. Extraction methods could not be compared due to unknown day-to-day variability in DNA extraction efficiency. ANOVA analysis was run on datasets without outliers.

\section{Availability of supporting data}

The dataset supporting the results of this article is included as an additional file to the manuscript (Additional file 5).

\section{Additional files}

Additional file 1: Table S1. DNA $A_{260} / A_{280}$ and $A_{260} / A_{230}$ absorbance ratios.

Additional file 2: Figure S1. Scatter Plot of $A_{260} / A_{280}$ and $A_{260} / A_{230}$ Ratios as a Function of a Control DNA (SRM 2372) Concentration. The experiments were executed on two separate days, $A$ and $B$ : with single (4 runs each) and triple (4 runs each) replicates respectively. The data point shape indicates day $A, \bullet, B, \boldsymbol{\Delta}$. The red vertical lines indicate the DNA concentration cutoff used for analysis of the DNA extract purity at $17.5 \mathrm{ng} / \mu \mathrm{L}$.

Additional file 3: Figure S2. Electropherograms for DNA Extracts Grouped by Cell Type and Extraction Method. The two manufacturer supplied markers are at $50 \mathrm{bp}$ and $17000 \mathrm{bp}$. Dotted lines indicate the 1000 bp point on the $x$-axis. The bottom number within each graph is the number of replicates where the area under the curve for the full electropherogram was above the analysis threshold. The top two numbers are the mean and standard deviation for the percentage of DNA that was greater than $1000 \mathrm{bp}$ (top value) and less than $300 \mathrm{bp}$ (middle value). Scales are independent for each row due to the large range in responses.

Additional file 4: Figure S3. Measured DNA concentration as a Function of the dilutions of the Human Quantification Standard (SRM 2372) concentration $(\mathrm{ng} / \mu \mathrm{L})$. Three dilution series replicates were processed, indicated in red, green, and blue, with five runs each. Dotted line indicates the defined limit of quantification $(0.25 \mathrm{ng} / \mu \mathrm{L})$ based on the increased observed variability for lower concentration dilutions.

Additional file 5: Raw data (sheet labeled "DNAcompleteResults. csv") and metadata (sheet labeled "Head descriptions") used to support the results presented in this article.

\section{Competing interests}

The author's declare no financial or non-financial conflicts of interest.

\section{Authors' contributions}

NDO and JMB conceived of the study and its design, performed the data analysis, and wrote the manuscript. NDO conducted the experiments. Both authors read and approved the final manuscript.

\section{Acknowledgements}

The authors would like to acknowledge Dr. Autumn Downey, Dr. Sandra da Silva, Jennifer McDaniel, and Lindsay Vang for assistance and guidance on the planning and execution of the project. Additionally, we would like to thank Drs. Marc Salit, James Filliben, and Steven Lund for their guidance with the statistical analysis; Drs. Erica Seifert and Sandra Da Silva for their comments and assistance during the writing process; as well Dr. David Duewer and Margaret Kline and the anonymous reviewers for reviewing the manuscript. Thanks to Dr. Peter Vallone for providing the Human DNA quantification standard (SRM 2732). The Department of Homeland Security (DHS) Science and Technology Directorate under the Interagency Agreement HSHQDC-09-X-00457 with the National Institute of Standards and Technology (NIST) supported this work. Opinions expressed in this paper are the authors' and do not necessarily reflect the policies and views of DHS, NIST, or affiliated venues. Certain commercial equipment, instruments, or materials are identified in this paper in order to specify the experimental procedure adequately. Such identification is not intended to imply recommendations or endorsement by NIST, nor is it intended to imply that the materials or equipment identified are necessarily the best available for the purpose.

Received: 25 July 2012 Accepted: 14 November 2012

Published: 3 December 2012

\section{References}

1. Espy MJ, Uhl JR, Sloan LM, Buckwalter SP, Jones MF, Vetter EA, Yao JDC, Wengenack NL, Rosenblatt JE, Cockerill FR III, Smith TF: Real-time PCR in clinical microbiology: applications for routine laboratory testing. Clin Microbiol Rev 2006, 19:165-256.

2. Rossmanith $\mathrm{P}$, Wagner $\mathrm{M}$ : The challenge to quantify Listeria monocytogenes-a model leading to new aspects in molecular biological food pathogen detection. J Appl Microbiol 2011, 110:605-617.

3. Holden MJ, Madej RM, Minor P, Kalman LV: Molecular diagnostics: harmonization through reference materials, documentary standards and proficiency testing. Expert Rev Mol Diagn 2011, 11:741-755.

4. Janse I, Hamidjaja RA, Bok JM, van Rotterdam BJ: Reliable detection of Bacillus anthracis, Francisella tularensis and Yersinia pestis by using multiplex qPCR including internal controls for nucleic acid extraction and amplification. BMC Microbiol 2010, 10:314.

5. Tan SC, Yiap BC: DNA, RNA, and protein extraction: the past and the present. J Biomed Biotechnol 2009, 2009:574398.

6. Kellogg M: Detection of biological agents used for terrorism: are we ready. Clin Chem 2010, 56(1):10-15. Epub 2009 Nov 19.

7. Wilfinger WW, Mackey K, Chomczynski P: Assessing the quantity, purity and integrity of RNA and DNA following nucleic acid purification. In DNA sequencing II optimizing preparation and cleanup. Edited by Sudbury KJ. MA: Jones and Bartlett Publishers; 2006:291-312.

8. Ning J, Liebich J, Kästner M, Zhou J, Schäffer A, Burauel P: Different influences of DNA purity indices and quantity on PCR-based DGGE and functional gene microarray in soil microbial community study. Appl Microbiol Biotechnol 2009, 82:983-993.

9. Sambrook J: The condensed protocols from molecular cloning: a laboratory manual. Cold Spring Harbor, NY: Cold Spring Harbor Laboratory Press; 2006.

10. Glasel JA: Validity of nucleic acids purities monitored by $260 \mathrm{~nm} / 280 \mathrm{~nm}$ absorbance ratios. Biotechniques 1994, 18:62-63. 
11. Simon MC, Gray DI, Cook N, Simon MC, Gray Dl: DNA extraction and PCR methods for the detection of Listeria monocytogenes in cold-smoked salmon. Appl Environ Microbiol 1996, 62:822-824.

12. Pinheiro LB, Coleman VA, Hindson CM, Herrmann J, Hindson BJ, Bhat S, Emslie KR: Evaluation of a droplet digital polymerase chain reaction format for DNA copy number quantification. Anal Chem 2012, 84:1003-1011.

13. Holden MJ, Rabb SA, Tewari YB, Winchester MR: Traceable phosphorus measurements by ICP-OES and HPLC for the quantitation of DNA. Anal Chem 2007, 79:1536-1541.

14. Brennan RG, Rabb S, Holden MJ, Winchester MR, Turk GC: Potential primary measurement tool for the quantification of DNA. Anal Chem 2009, 81:3414-3420

15. EURACHEM: The fitness for purpose of analytical methods a laboratory guide to methods validation and related topics. UK: LGC Ltd; 1998.

16. Holden MJ, Haynes RJ, Rabb SA, Satija N, Yang K, Blasic JR: Factors affecting quantification of total DNA by UV spectroscopy and picogreen fluorescence. J Agric Food Chem 2009, 57:7221-7226.

17. Singer $V L$, Jones LJ, Yue ST, Haugland RP: Characterization of picogreen reagent and development of a fluorescence-based solution assay for double-stranded DNA quantitation. Anal Biochem 1997, 249:228-238.

18. Hospodsky D, Yamamoto N, Peccia J: Accuracy, precision, and method detection limits of quantitative PCR for airborne bacteria and fungi. Appl Environ Microbiol 2010, 76:7004-7012.

19. Griffiths KR, Burke DG, Emslie KR: Quantitative polymerase chain reaction: a framework for improving the quality of results and estimating uncertainty of measurement. Anal Method 2011, 3:2201.

20. Dauphin LA, Hutchins RJ, Bost LA, Bowen MD: Evaluation of automated and manual commercial DNA extraction methods for recovery of Brucella DNA from suspensions and spiked swabs. J Clin Microbiol 2009, 47:3920-3926.

21. Dauphin LA, Moser BD, Bowen MD: Evaluation of five commercial nucleic acid extraction kits for their ability to inactivate Bacillus anthracis spores and comparison of DNA yields from spores and spiked environmental samples. J Microbiol Methods 2009, 76:30-37.

22. Dauphin LA, Stephens KW, Eufinger SC, Bowen MD: Comparison of five commercial DNA extraction kits for the recovery of Yersinia pestis DNA from bacterial suspensions and spiked environmental samples. J Appl Microbiol 2010, 108:163-172.

23. Fahle GA, Fischer SH: Comparison of six commercial DNA extraction kits for recovery of cytomegalovirus DNA from spiked human specimens. J Clin Microbiol 2000, 38:3860-3863.

24. Whitehouse CA, Hottel HE: Comparison of five commercial DNA extraction kits for the recovery of Francisella tularensis DNA from spiked soil samples. Mol Cell Probes 2007, 21:92-96.

25. Queipo-Ortuño MI, Tena F, Colmenero JD, Morata P, Queipo-Ortuno MI: Comparison of seven commercial DNA extraction kits for the recovery of Brucella DNA from spiked human serum samples using real-time pcr. Eur J Clin Microbiol Infect Dis 2008, 27:109-114.

26. Miller DN, Bryant JE, Madsen EL, Ghiorse WC: Evaluation and optimization of DNA extraction and purification procedures for soil and sediment samples. Appl Environ Microbiol 1999, 65:4715-4724.

27. Swango KL, Timken MD, Chong MD, Buoncristiani MR: A quantitative PCR assay for the assessment of DNA degradation in forensic samples. Forensic Sci Int 2006, 158:14-26.

28. Tung N-H, Aboudharam G, Drancourt M: Heat degradation of eukaryotic and bacterial DNA: an experimental model for paleomicrobiology. BMC Res Notes 2012, 5:528.

29. Nolan T, Hands RE, Ogunkolade W, Bustin SA: SPUD: A quantitative PCR assay for the detection of inhibitors in nucleic acid preparations. Anal Biochem 2006, 351:308-310.

30. Li R, Mock R, Huang Q, Abad J, Hartung J, Kinard G: A reliable and inexpensive method of nucleic acid extraction for the PCR-based detection of diverse plant pathogens. J Virol Methods 2008, 154:48-55.

31. Kim HS, Byun SH, Lee BM: Effects of chemical carcinogens and physicochemical factors on the UV spectrophotometric determination of DNA. J Toxicol Environ Health A 2005, 68:2081-2095.

32. Kushner SR: MRNA decay in prokaryotes and eukaryotes: different approaches to a similar problem. IUBMB Life 2004, 56:585-594.

33. Boehm AB, Yamahara KM, Love DC, Peterson BM, McNeill K, Nelson KL: Covariation and photoinactivation of traditional and novel indicator organisms and human viruses at a sewage-impacted marine beach. Environ Sci Technol 2009, 43(21):8046-8052.

34. Lim DV, Kearns EA, Leskinen SD, Magana S, Stroot JM, Hunter DM, Schlemmer SM: Sample preparation and assay refinements for pathogen detection platforms. Proc SPIE 2009, 7167:716700-716700. 71610.

35. Courtois S, Frostegård A, Göransson P, Depret $G$, Jeannin P, Simonet P: Quantification of bacterial subgroups in soil: comparison of DNA extracted directly from soil or from cells previously released by density gradient centrifugation. Environ Microbiol 2001, 3:431-439.

36. Wilson IG: Inhibition and facilitation of nucleic acid amplification. Appl Environ Microbiol 1997, 63:3741-3751.

37. Mahuku GS: A simple extraction method suitable for PCR - based analysis of fungal and bacterial DNA. Plant Mol Biol Rep 2004, 22:71-81.

38. Arbeli Z, Fuentes CL: Improved purification and PCR amplification of DNA from environmental samples. FEMS Microbiol Lett 2007, 272:269-275.

39. Pontiroli A, Travis ER, Sweeney FP, Porter D, Gaze WH, Mason S, Hibberd V, Holden J, Courtenay O, Wellington EMH: Pathogen quantitation in complex matrices: a multi-operator comparison of DNA extraction methods with a novel assessment of PCR inhibition. PLoS One 2011, 6:e17916.

40. Huggett JF, Novak T, Garson JA, Green C, Morris-Jones SD, Miller RF, Zumla A: Differential susceptibility of PCR reactions to inhibitors: an important and unrecognized phenomenon. BMC Res Notes 2008, 1:70.

41. Opel KL, Chung D, McCord BR: A study of PCR inhibition mechanisms using real time PCR. J Forensic Sci 2010, 55:25-33.

42. Carbonero F, Nava GM, Benefiel AC, Greenberg E, Gaskins RH: Microbial DNA extraction from intestinal biopsies is improved by avoiding mechanical cell disruption. J Microbiol Methods 2012, 87:125-127.

43. Mumy KL, Findlay RH: Convenient determination of DNA extraction efficiency using an external DNA recovery standard and quantitativecompetitive PCR. J Microbiol Methods 2004, 57:259-268.

44. Carrigg C, Rice O, Kavanagh S, Collins G, O'Flaherty V: DNA extraction method affects microbial community profiles from soils and sediment. Appl Microbiol Biotechnol 2007, 77:955-964

45. Sauer P, Muller M, Kang J: Quantitation of DNA. Qiagen News 1998, 2:23-26

46. Nolan T, Hands RE, Bustin SA: Quantification of mRNA using real-time rtPCR. Nat Protoc 2006, 1:1559-1582.

47. Demeke T, Jenkins GR: Influence of DNA extraction methods, PCR inhibitors and quantification methods on real-time PCR assay of biotechnology-derived traits. Anal Bioanal Chem 2010, 396:1977-1990.

48. Rothrock MJ Jr: Comparison of microvolume DNA quantification methods for use with volume-sensitive environmental DNA extracts. J Nat and Environ Sci 2011, 2:34-38.

49. De Mey M, Lequeux G, Maertens J, De Maeseneire S, Soetaert W, Vandamme E: Comparison of DNA and RNA quantification methods suitable for parameter estimation in metabolic modeling of microorganisms. Anal Biochem 2006, 353:198-203.

50. Nielsen K, Mogensen HS, Hedman J, Niederstätter H, Parson W, Morling N: Comparison of five DNA quantification methods. Forensic Sci Int Genet 2008, 2:226-230

51. Käser M, Ruf M-T, Hauser J, Marsollier L, Pluschke G: Optimized method for preparation of DNA from pathogenic and environmental mycobacteria. Appl Environ Microbiol 2009, 75:414-418

52. Koponen JK, Turunen A-M, Ylä-Herttuala S: Escherichia coli DNA contamination in amplitaq gold polymerase interferes with taqman analysis of lacZ. Mol Ther 2002, 5:220-222.

53. Martínez-Blanch JF, Sánchez G, Garay E, Aznar R: Detection and quantification of viable bacillus cereus in food by rt-qPCR. Eur Food Res Technol 2011, 232:951-955

54. Hierro N, Esteve-Zarzoso B, González A, Mas A, Guillamón JM: Real-time quantitative PCR (qPCR) and reverse transcription-qPCR for detection and enumeration of total yeasts in wine. Appl Environ Microbiol 2006, 72:7148-7155.

55. Rajendhran J, Gunasekaran P: Strategies for accessing soil metagenome for desired applications. Biotechnol Adv 2008, 26:576-590.

56. Purohit MK, Singh SP: Assessment of various methods for extraction of metagenomic DNA from saline habitats of coastal gujarat (India) to explore molecular diversity. Lett Appl Microbiol 2009, 49:338-344.

57. Manjula A, Sathyavathi S, Gunasekaran P, Rajendhran J: Comparison of seven methods of DNA extraction from termitarium for functional metagenomic DNA library construction. Ind Res 2011, 70:945-951. 
58. Da Silva SM, Filliben JJ, Morrow JB: Parameters affecting spore recovery from wipes used in biological surface sampling. Appl Environ Microbiol 2011, 77:2374-2380.

59. Sprague LD, Zysk G, Hagen RM, Meyer H, Ellis J, Anuntagool N, Gauthier Y, Neubauer $\mathrm{H}$ : A possible pitfall in the identification of burkholderia mallei using molecular identification systems based on the sequence of the flagellin fliC gene. FEMS Immunol Med Microbiol 2002, 34:231-236.

60. Hellemans J, Mortier G, De Paepe A, Speleman F, Vandesompele J: Qbase relative quantification framework and software for management and automated analysis of real-time quantitative PCR data. Genome Biol 2007, 8:R19.

61. Dolezel J, Bartos J, Voglmayr H, Greilhuber J: Nuclear DNA content and genome size of trout and human. Cytometry A 2003, 51:127-128. author reply 129 .

doi:10.1186/1756-0500-5-668

Cite this article as: Olson and Morrow: DNA extract characterization process for microbial detection methods development and validation. BMC Research Notes 2012 5:668.

\section{Submit your next manuscript to BioMed Central and take full advantage of:}

- Convenient online submission

- Thorough peer review

- No space constraints or color figure charges

- Immediate publication on acceptance

- Inclusion in PubMed, CAS, Scopus and Google Scholar

- Research which is freely available for redistribution 